\title{
Atık Camların Kalıpla Şekillendirme Tekniğinde Kullanımı
}

\author{
Using of Glass Waste in Mold Glass Forming Technique
}

\section{Selvin Yeşilay ${ }^{*}$, Özge Biçer*}

\section{Öz}

Cam, kimyasal, termal, mekanik, optik ve estetik özellikleri nedeniyle insanlık tarafından binlerce yıldır geniş bir uygulama yelpazesinde kullanılmaktadır. Asırlardan beri sanatsal ve endüstriyel olarak birçok nesnenin yapı taşı camdır. Keşfi Antik Mısır ve Mezopotamya uygarlıklarına kadar dayanan cam, doğadan elde edilen ham maddelerin yüksek sıcaklıkta eritilerek ürüne dönüştürülmesi sonucu oluşmaktadır. Oldukça zor bir üretim aşamasından geçmektedir. Günümüzde cam çok yaygın kullanılan bir malzemedir ve geri dönüşümü yapılan başlıca malzemelerden biridir.

Artan insan nüfusuna paralel olarak tüketim ihtiyacının dengelenebilmesi için geri dönüşümle ilgili çalışmaların sayısı oldukça artmıştır. Sanayileşmiş ülkelerin, en büyük sorunlarından birisi, artan kaynak tüketimine bağlı olarak doğal dengenin bozulmasıdır. Ham maddelerin tüketilmesi ile oluşan toprak, hava ve su kirliliği, çevresel sorunların başında gelmektedir. Katı atıkların ayrıştırılarak geri dönüşümlerinin sağlanması ile ülke ekonomisine destek verilerek çevre kirliliğinin azalmasına yardımcı olunur. Ayrıca hammadde tasarrufu sağlanır.

Bu çalışma kapsamında da sonsuz kere dönüşümü sağlanan camın, işletme ve ambalaj atıkları farklı bir yaklaşım olarak kalıpla şekillendirme tekniklerinde kullanılarak, özgün tasarımlar üretilmiştir.

\section{Anahtar Kelimeler}

Cam sanatı, Atık camlar, Kalıpla şekillendirme, Geri dönüşüm

\section{Abstract}

Glass has been used by humanity for thousands of years in a wide range of applications due to its chemical, thermal, mechanical, optical, and aesthetic properties. It has been the building block of many objects, both artistic and industrial, for centuries. Glass, whose discovery dates back to Ancient Egypt and Mesopotamian civilizations, is formed by melting raw materials obtained from nature at high temperature and turning them into products. It goes through a rather difficult production stage. Today, glass is a very common material and has been one of the main materials recycled.

In parallel with increasing human population, the number of studies on recycling has increased considerably in order to balance consumption needs. One of the biggest problems of industrialized countries is the deterioration of the natural balance due to increasing resource consumption. Soil, air, and water pollution caused by consumption of raw materials are primary environmental problems. Recycling of solid waste supports a country's economy and helps reduce environmental pollution. In addition, raw material is saved.

Within the scope of this study, the factory and packaging waste of glass recycled many times was used in mold forming techniques that produced original designs.

\section{Keywords}

Glass art, Waste glass, Mold Glass forming, Recycling

* Sorumlu Yazar: Selvin Yeşilay (Dr. Öğr. Üyesi), Anadolu Üniversitesi, Güzel Sanatlar Fakültesi, Cam Bölümü, Eskişehir, Türkiye. E-posta: selvin.yesilay@gmail.com ORCID: 0000-0002-8217-3874

** Özge Biçer (Yüksek Lisans Öğrencisi), Anadolu Üniversitesi, Güzel Sanatlar Fakültesi, Cam Bölümü, Eskişehir, Türkiye. E-posta: ozgebicer3@gmail.com ORCID: 0000-0003-0777-9646

Atıf: Yesilay, Selvin ve Bicer, Ozge. “Atkk Camların Kalıpla Şekillendirme Tekniğinde Kullanımı." Art-Sanat, 14(2020) 579-596. https://doi.org/10.26650/artsanat.2020.14.0022 


\section{Extended Summary}

Glass, which has been around for a long time, served as one of the first discoveries of handicrafts, a fascinating material of naturalness, purity, and aesthetics. This unique material encountered in both industrial and artistic fields for centuries, has applications in many different techniques since its discovery, adapted to ever-evolving technology, and expanded its usage areas. Advances in technology have led to an increase in production speed and diversity, and hence an increase in consumption.

It is formed by melting raw materials such as glass, sand, soda, feldspar and lime at high temperatures. Glass behavior is related to the microstructures of materials, that is, the atomic order. In glass, atoms are arranged in a certain order in unit size. However, this order is not preserved at long distance. The basic unit structure of glass is silica tetrahedron, which consists of a single silicon atom surrounded by four oxygen atoms. Silicon has a valence value of +4 and consists of regular tetrahedra with a silicon atom in the center and four oxygen atoms around it. Atoms are bonded by ionic and covalent bonds. Glass contains more than one oxide. These oxides are generally classified in 3 groups as; Glass Forming Oxides, Modifying Oxides, and Conditional Glass Makers. Glass has high viscosity even at high temperature with an inorganic-based silicate system that solidifies without crystallization at normal temperature.

While the natural resources of these raw materials are decreasing day by day, they cause environmental problems such as energy spent, water, and soil pollution. In parallel with the growing human population, the number of studies on recycling has increased significantly to offset consumption needs. One of the biggest problems of industrialized countries is deterioration of the natural balance due to increased resource consumption. Soil, air, and water pollution caused by raw material consumption is the main environmental problem.

By transforming solid wastes, a country's economy is supported and environmental pollution is reduced. In addition, raw material is saved. Recycling is the process of converting waste that can be recycled to secondary raw materials through various separation stages. Recycling in glass will contribute to the reduction of energy spent during production and the prevention of air pollution and excess water consumption by ensuring the protection of primary raw material resources. Glass can be recycled infinitely without compromising on quality with each conversion. Waste glass is not only transformed for the glass industry. Apart from this, it is also used in the construction industry, in the production of asphalt materials, and in many areas as decorative material. Thus, recycled waste glass contributes to the national economy and environmental protection.

Within the scope of this study, glass operation and packaging waste was used as a different approach in mold forming techniques, which have an important place in glass 
art. In order to avoid the thermal expansion coefficient incompatibility, glass from the same production was preferred in the enterprise. Within the scope of the studies, only two types of compatible glass was used together. Expansion coefficients of the two types of glass was very close to each other. No cracking or breakage was observed on the surface of the glass after use. Mold forming techniques are defined as the process of removing models from the mold by filling them with glass after firing the molds of the desired models with heat resistant materials. The technique has its origins in Mesopotamian and Egyptian civilizations.

Many years after its discovery, it was put into practice by artist Henri Cross and emerged as an improved firing technique. This technique is created by preparing a model first. The prepared model can be made from many different materials. The most preferred modeling products for this technique are clay, beeswax, silicon, or plaster. After the model is made, its weight is calculated and the amount of glass required is determined. Plaster and silica etc. are used in mold making after the modeling. The materials are heat resistant refractory materials. Different materials supporting plaster and silica can be added for mold removal. After removing the mold, if the model is made of wax, the wax is melted with water vapor and removed from the mold. In this emptied area, glass as much as the weight of the model is added and put into the oven. Glasses are completely fused with the effect of temperature in the oven and a filled surface is obtained. It was possible to find many artists in the world who use waste glass in different techniques and evaluate them artistically. It was observed that waste glass was turned into art objects by using techniques such as glass forming with open flame, stained glass, mosaic, and fusion. The mold forming method is an important technique that requires effort in terms of material usage and the construction process. 


\section{Giriş}

Keşfinden bu yana insan hayatının vazgeçilmez bir parçası olarak varlığını sürdüren cam, görüntüsü ile cezbederken, mukavemeti, sertliği, esnekliği, termal şoklara ve aşınmaya karşı direnci sayesinde son derece kullanışlı bir malzeme olarak insan hayatında yerini almıştır ${ }^{1}$. Cam, ssıtılınca akışkanlık kazanan, ama soğuyarak sertleşen, saydam, mat ve kırılabilen bir malzemedir. Cam, malzemesinden ileri gelen bu özelliklerle 'hızlı' biçimlendirilmesi gereken bir yapıdadır'. Pencere camları, sofra takımları ve opto-elektronikte yaygın olarak kullanılan pratik, teknolojik ve dekoratif kullanıma sahip, kristal olmayan amorf bir katıdır. Çağlar boyunca doğallığın, saflığın ve aydınlığın simgesi olan cam, günümüzde yenilikçilik, basitlik, denge, hafiflik, dinginlik, sadelik ve gösteriş kavramları ile ön plana çıkmaktadır . Gündelik yaşantımızın her alanında sayısız fayda sağladığımız cam, aynalardan sokak lambalarına, sofra eşyalarından ileri teknoloji ürünlerine kadar hayatımızın her alanına ışık tutmuş bir malzemedir.

Camın kimyası çok karmaşıktır. Silis (silisyum dioksit- Sio2) camın ana maddesidir. Yalnız saf silisin ergime 1sısı çok yüksek olduğundan (yaklaşık 1725 derece) ergime 1sısını düşürmek için harmana alkali maddelerin ilave edilmesi gerekir ${ }^{4}$. Böylelikle camı, alkali ve toprak alkali metal oksitlerinin ergitilmesiyle elde edilen ${ }^{5}$, ani soğuma sonucunda kristallenme olmaksızın katılaşan ${ }^{6}$, homojen yapıda, inorganik bir ergime ürünü ${ }^{7}$ olarak tanımlayabiliriz. Siradan bir cam, silisyum dioksit, potasyum karbonat, sodyum karbonat ve kalsiyum karbonat gibi çeşitli maddelerin bileşiminden oluşur .

İnsanoğlunun yaşamsal faaliyet alanlarıyla sınırlı kalmayan cam, aynı zamanda önemli bir sanat malzemesi hâline gelmiştir. Üretim sırasında sayısız farklılıkta özellikler sunması nedeniyle sanatçıya sınırsız ifade olanakları elde etme imkânı verir9 . Günümüze kadar sürdürdüğü bu yolculukta fiziksel ve kimyasal özellikleri dışında, özgün tasarımların oluşması için büyük bir ustalıkla, becerikli ellerde biçimlendirilmiştir. Tarihinin her döneminde gelişme göstermiş, farklı teknikler ile üretilmiş ve bugün tüm dünyada cam sanatı önemli bir yere sahip olmuştur.

1 Elif Gökçigdem, "Fragile Beauty: Islamic Glass," Saudi Aramco World (May/June 2002), erişim 27 Ocak 2020, https://archive.aramcoworld.com/issue/200203/fragile.beauty-islamic.glass.htm

2 Önder Küçükerman, Cam ve Çağdaş Tasarım İçindeki Yeri (İstanbul: Paşabahçe Ticaret Limited, 1977), 17.

3 Selvin Yeşilay, "Cam Dekorasyon Teknikleri“, Anadolu Sanat Dergisi 19 (2008), 111.

4 Üzlifat Canav Özgümüş, Çağlar Boyu Cam Tasarımı (İstanbul: Arkeoloji ve Sanat Yayınları, 2013), 1.

5 Esin Küçükbiçmen, "Cam Şekillendirme Yöntemleri ve Kişisel Yorumlar” (Sanatta Yeterlilik Tezi, Anadolu Üniversitesi, 2005), 4; Güner Sümer, Cam Teknolojisi (Eskişehir: [y.y], 2007), 1.

6 Yusuf Öbelik, "Cam Hammaddesi Mineralojisi ve Cam Teknolojisi” (Yüksek Lisans tezi, Niğde Üniversitesi, 2011), iii.

7 Zerrin Aydın Tavukçu, "Parion Güney Nekropolü'nden Bir Grup Cam Eser," Atatürk Üniversitesi Güzel Sanatlar Fakültesi Dergisi 12 (2007), 146.

8 Barış Emre Sönmez, "Nevşehir Müzesi’nde Bulunan Cam Unguentariumlar," Uluslararası Sosyal Araş̧tırmalar Dergisi 41 (2015), 734

9 Selvin Yeşilay ve Ufuk Akbey, "Cam Dekorasyonunda Alternatif Bir Malzeme Olarak Uçucu Kül Kullanımının Araştırılması," Sanat ve Tasarım Dergisi 20 (2017), 302. 
Artan insan nüfusuyla birlikte farklı sanayi kollarının üretim oranları gün geçtikçe artmaktadır. Bu nedenle, üretim sırasında meydana gelen atıkların bertaraf edilme seviyesi, depolanması, nakliyesi ve atıkların yeniden değerlendirilmesiyle ilgili çalışmalar çevresel ve ekonomik açıdan kaçınılmaz konular olarak göz önünde bulundurulmalıdir ${ }^{10}$.

Küresel anlamda ilk olarak atık oluşumunun önlenmesi ve azaltılması, ardından atıkların yeniden kullanımının sağlanması yönünde çalışmalar yapılmalıdır. Halkı bilinçlendirmek için uygulanan politikalar, atık oluşumunu engellemek ve oluşan atıkların tekrar kullanılabilir olanlarının kullanıma geri kazandırılması ya da farklı kullanım alanlarının oluşturulmasına yardımcı olmayı kapsamaktadır. Tekrar kullanımı mümkün olmayan atıklar, geri dönüşüm ve geri kazanım süreçlerine dâhil edilmiştir. Geri dönüşümü mümkün olan atıklar; evsel, tıbbi, tehlikeli ve tehlikesiz atıklar olarak kaynağından toplanarak ayrıştırılır ve geri dönüşümü sağlanır. Bu zincirin en son halkasında geri dönüşümü mümkün olmayan atıkların bertaraf edilmesi yer alır.

İlk üretilen cam antik Mezopotamya'da bulunmuş ve o zamandan beri üretimi, kaçınılmaz olarak büyük atık oranlarına yol açan muazzam kapasitelere ulaşmıştır ${ }^{11}$. Cam, ambalaj veya cam kap, düz cam, ampul camı, fiber optik kablolar, güneş panelleri, cam levhalar, vakum tüpleri ve katot 1şınlı tüp camları dâhil olmak üzere birçok formda üretilir ${ }^{12}$. Camın kullanım alanlarındaki artış, büyük ölçüde değişen özelliklere sahip farklı cam türlerinin keşfinden kaynaklanmaktadır. Bu cam türlerinin her biri, üretildikleri formda sınırlı bir ömre sahiptir ve çevresel sorunları önlemek için yeniden kullanılmaları gerekir ${ }^{13}$. Camın geri dönüşümü, sonu olmayan bir döngüye sahiptir. Plastik ve kağıt atıkların aksine camlar sonsuz kere yeniden üretime dâhil edilebilirler. Tüketim sonrası ortaya çıkan camlar, katı atıkların büyük bir bölümünü oluşturmaktadır ${ }^{14}$. Cam kırığı, düşük ekonomik değeri olan hurda cam olarak tanımlanmaktadır ${ }^{15}$. Geri dönüşümü yapılmayan atık camlar depolama sahalarında çok uzun

10 Münevver Çakı, Bekir Karasu, Selvin Yeşilay, Rahmi Irmak ve Canbora Bayraktar. "The Use of Fired Roof Tile and Brick Wastes in Stoneware Bodies as Alternative Raw Maretials," Proceedings of the Rewas 2008 Global Symposium on Recycling, Waste Treatment and Clean Tecnology. Ed. Brajendra Mishra, C. Ludwig and Subodh K. Das (USA: The Minerals, Metals \& Materials Society, 2008), vol. 3, 1541-1548.

11 Viviana Letelier, Bastian I. Henriquez- Jara, Miguel Manosalva, Camila Parodi and Jose Marcos Ortega, "Use of Waste Glass as A Replacement for Raw Materials in Mortars with a Lower Environmental Impact," Energies 12 (2019), 1.

12 Nur Liza Rahim, Roshazita Che Amat and Norlia Mohamad Ibrahim. "Utilization of Recycled Glass Waste as Partial Replacement of Fine Aggregate in Concrete Production," Materials Science Forum 20 (2015), 16-20.

13 Abbas Mohajerani, John Vajna, Tsz Ho Cheung, Halenur Kurmus, Arul Arulrajah and Suksun Horpibulsuk. "Practical Recycling Applications of Crushed Waste Glass in Construction Materials: A Review," Construction Building Materials 156 (2017), 443-467.

14 Yunping Xi, Yue Li, Zhaohui Xie, and Jae S. Lee, "Utilization of Solid Wasted (Waste Glass and Rubber Particles) as Aggregates in Concrete", Proceedings of the International Workshop on Sustainable Development and Concrete Technology, Ed. Kejin Wang (ABD: Iowa State University, 2004), 45-54.

15 Ayşe Öz, “Camın Geri Dönüşüm Süreci ve Çevre,” Mart 2007, erişim: 7 Kasım 2018. http://www.kocaeliaydinlarocagi.org.tr/Yazi/Detay/32 
süre kalırlar. Cam şişelerin ayrışması yaklaşık 1 milyon yıl alır ve bu süre içerisinde biyolojik olarak parçalanabilen malzemeler için kullanılabilecek değerli alanlar kullanılmış olur ${ }^{16}$. Sonuç olarak atık camların geri dönüştürülmesine ve yeniden kullanılmasına güçlü bir ihtiyaç vardır. Atıkların yapı malzemesi ve inşaat sektörü gibi alanlarda kullanılmasına yönelik araştırmaların artması, doğal kaynakların tüketiminin ve depolama alanlarının azaltılmasına yardımcı olacaktır ${ }^{17}$. Atık camların yeniden cam üretiminde geri dönüşümlerinin sağlanması dışında farklı alanlardaki kullanımlarının araştırılmasıyla ilgili çalışmaların önemi büyüktür.

Atık camların dünyanın birçok bölgesinde farklı tekniklerde kullanımına rastlanmaktadır. Endonezya'da yaşayan Ivan Bestari Minar Pradipta, 2011 y1lından bu yana geri dönüşüm camları ile çalışmış ve 2015 yılında Pseudomorph Recycled Glass Flameworking adlı kişisel sergisini açmıştır. Açık alevle şekillendirme tekniklerini kullanarak çalışmalarını Yogyakarta'daki Studio Otakatik'te uygulamıştır. Ağırlıklı olarak iç dekorasyon ve çeşitli aksesuarlar yaptığını vurgulamıştır. Geri dönüşüm camları ile çalışırken zorlanmış, fakat zorluğuna rağmen, tüm sınırlarını zorladığını ifade etmiştir $^{18}$. Şişe tabanları, eski avizeler, antika camlar ve lamba parçalarını kullanarak eserler oluşturmuş bir diğer sanatçı da Alison Fox'tur. Fox, her zaman antika dükkânlarını ve halk pazarlarını dolaştığını ifade eder. Eski cam çerçevelerini toplayarak, aydınlatma ve cam paneller ile eserlerini oluşturmuştur. Geri dönüşüm camlarını vitray teknikleri ile hayata geçirmiştir. Sanatçı Nikki Ella Whitlock atık camları mozaik tekniğinde kullanmışıır ${ }^{19}$. Yaklaşık 20 yıldır ateşle atık camları buluşturan İsmail Şenol, Bodrum'da ürettiği nazar boncuklarını atık camları kullanarak yaptığını ifade etmiştir. Atık camları toplayıp bu camları $600-1000{ }^{\circ} \mathrm{C}$ de eriterek balık, damla küpe ve anahtarlık gibi şekiller verdiğini belirtir ${ }^{20}$. Bu sanatçıların haricinde Brent- Shirly Cairns, Cindy Ann Coldiron, Jennifer Hecker, Bill Hess, Dolnald S. Kolberg, Catherine Lottes, Jason Mack, Sol Mesz, Bryan Northup, Ervin Timmers, Mark Wotherspoon gibi sanatçılar atık camlar ile farklı tekniklerde çalışmaktadır.

Bu çalışmada kalıp içi cam şekillendirme tekniklerinde çeşitli ambalaj atıklarının geri dönüşümleri gerçekleştirilerek, tasarımlar yapılmış ve sanatsal üretimler gerçekleştirilmiştir. Camın ilk keşfedildiği zamanlarda çok yaygın olarak karşımıza çıkmayan kalıpla şekillendirme teknikleri ilerleyen dönemlerde önemli gelişmelere tanıklık

16 Mohajerani Vajna, Cheung Kurmus and Arulrajah Horpibulsuk, "Practical Recycling Applications of Crushed Waste Glass in Construction Materials: A Review," 443-467.

17 Mohajerani Vajna, Cheung Kurmus and Arulrajah Horpibulsuk, "Practical Recycling Applications of Crushed Waste Glass in Construction Materials: A Review," 447.

18 "Ivan Bestari and Otakatik Studio Color Pattern Artwork Miniature Sculpture Glass Materials," Technology Policy Update, erişim: 5 Kasım 2019, https://www.tinuku.com/2016/09/23.html

19 “Glass Bottle Windows," Insteading, erişim 5 Kasım 2019, https://insteading.com/blog/recycled-glassbottles/

20 “Bodrum'da Atık Camlar Sanata Dönüşüyor," Haberler, erişim 5 Kasım 2019, https://www.haberler.com/ atik-camlar-sanata-donusuyor-6212913-haberi/ 
etmiş ve tekniklerin gelişmesi ile birlikte camın tarihsel süreçteki gelişimine katkıda bulunmuştur. Teknik çeşitli malzemelerden yapılan modellerin, 1sıya dayanıklı malzemeler ile kalıplarının alınmasıyla kalıptan çıkartılması ve hazırlanan camların kalıp içerisine yerleştirilerek firınlanması şeklinde uygulanmaktadır.

Cam yapımının ilk 2000 yıllık sürecinde fırında cam şekillendirme ve benzer üretim teknikleri hâkimdir. Ayrıca cam, iki büyük medeniyet olan Mezopotamya ve Misır'ın hizmetinde olmuştur ${ }^{21}$. Bu dönemlerde, cam kâse ve kapların var olduğu bilinse bile, cam heykel yapımı yok denecek kadar azdır. 1850'li yıllarda Henry Cross tarafından firınlama tekniğ ${ }^{22}$ uygulanmıştır. Genel olarak teknik, 1sıya dayanıklı bir kalıbın içinde camın fırınlanıp ergitilmesi ile gerçekleştirilen bir şekillendirilme yöntemi olarak tanımlanır ${ }^{23}$. Çağdaş uygulamalarda evrensel olarak en fazla gözlemlenen şey, fırında biçimlendirmenin bir döküm yöntemi olarak ön plana çıkmasıdır. Son on yılda kalıpların yapımı ve bileşimiyle ilgili araştırmaların artması dolayısıyla bu baskınlık daha da belirgin hâle gelmiştir. Uygulanan varyasyonlar, bazı faktörlere ve bunların arasındaki etkileşime bağlıdır. Bunlar; kullanılan camın türü, formun boyutu ve kurgusu, camın çalışma sıcaklığı aralığı, camın şekli (tabaka, çubuk, granül, toz) ve nihai üründen beklenen nitelikleridir ${ }^{24}$. Fırında cam şekillendirme tekniklerinde önemli olan bir modelin olmasıdır. Bu modeller çeşitli malzemelerden tercih edilmektedir. Bunlardan en çok kullanılanları; kil, mum, silikon, alçı, strafor gibi malzemelerdir. Kullanılan modelin kalıbı alındıktan sonra model kalıbın içerisinden çıkartılır ve oluşan boşluk cam ile doldurularak fırınlanır. Fırında cam şekillendirme yöntemlerinde tercih edilen kalıp şekli tek parçalı olanlardır. Çok parçalı kalıplarda kullanılan kalıp malzemesi 1sı karşısında deformasyona uğradığı için, düzgün bir yüzey eldesini zorlaştırmaktadır. Atölye çalışmaları sırasında modellemelerde balmumu kullanılmıştır.

\section{Atölye Çalışmaları}

Çalışmada, ambalaj atıkları ve işletme atıklarının kalıp içi cam şekillendirme tekniklerinde kullanılarak sanatsal üretimde geri dönüşümlerinin sağlanması hedeflenmiştir. İlk aşamada balmumu kullanılarak modeller üretilmiştir (G. 1.).

21 Keith Cummings, Techniques of Kiln-formed Glass (ABD: University of Pennsylvania Press, 1997), 23.

22 Bilgehan Uzuner, Bulunuşundan Üflemeye Cam Teknikleri (İstanbul: İnkılap Kitabevi, 2004), 26-27.

23 Necati Şenok, "Pate De Verre Cam Şekillendirme Tekniği ile Cam Sanat objeleri Araştırma ve Uygulamaları" (Yüksek Lisans tezi, Çukurova Üniversitesi, 2011), 25.

24 Keith Cummings, Çağdaş Cam Sanatı Fırın Teknikleri ve Uygulamalar, çev. Mustafa Ağatekin (İzmir: Karakalem Kitabevi, 2011), 193. 


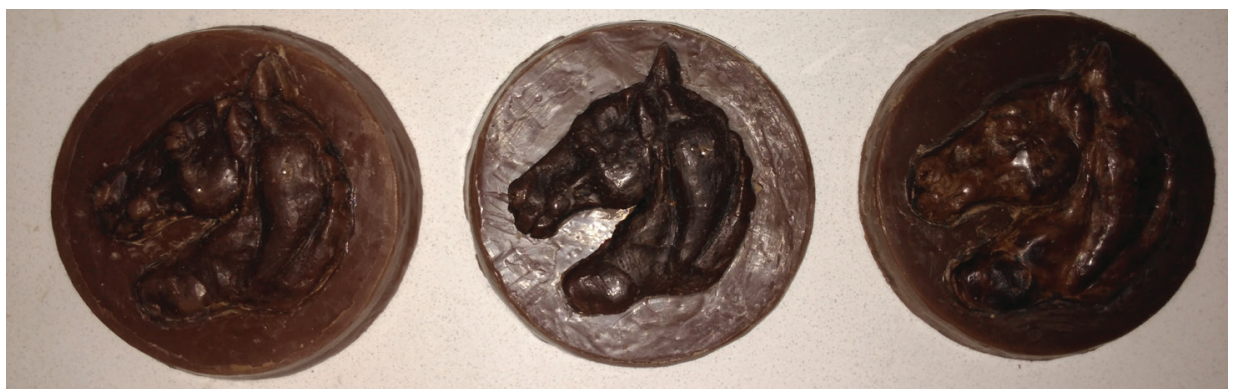

G. 1. Balmumundan yapılan üç adet model çalışması (Özge Biçer, 2018)

Modeller tamamlanmış ve her bir model için harcanacak cam miktarı hesaplanmıştır. Bir kaba belirli bir hizaya kadar su doldurulmuştur. Doldurulan kabın su seviyesi işaretlenmiştir. Ardından bir model suya batırılmış ve suyun yükseklik hizası işaretlenerek model kaptan çıkartılmıştır. Bu iki işaretlenen çizginin arası cam ile doldurulmuş ve bir model için harcanan camın miktarı belirlenmiştir. Burada dikkat edilmesi gereken bir husus da, açık kalıplarda hazırlanan modelin yüzünün çalışma alanının üzerine bakacak şekilde yerleştirilmesidir. Bu teknik, tek yöne sahip, az ayrıntısı bulunan modeller için uygun bir yöntemdir.

Burada anlaşılması gereken önemli nokta, fırınlama işleminde, kalıp ağzının yukarıda kalabilmesi için kalıp alımı sırasında modelin ağzı aşağıda kalacak şekilde işleminin gerçekleştirilmesidir ${ }^{25}$. Kalıpların alınacağı yer arap sabunu ile silinmiştir. Bunun amacı, hazırlanan alçı karışımının yüzeye yapışmasını engellemektir. Modeller döküm sırasında yerinden oynamamaları için yüzeye kil yardımı ile sabitlenmiştir. Kalıbı alınacak modellerin kurguları kurulup yüzeyde sabit kalabilmeleri için, küçük bir kaba hızlıca su ve alçı karıştırılıp kenar kısımlarına sürülmüştür (G. 2).

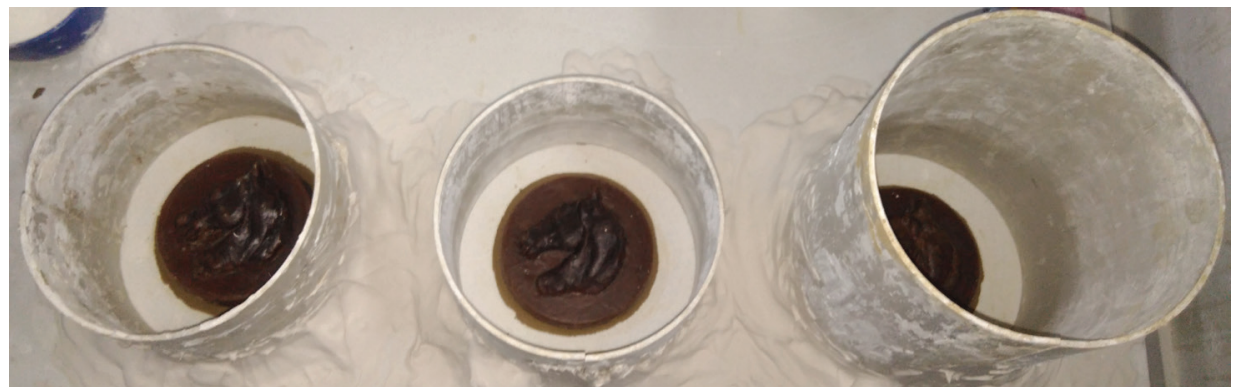

G. 2. Kalıp alma işlemi (Özge Biçer, 2018)

Modellerin alçılarını hazırlamak için, bir kovanın içerisine üç modele yetecek kadar su konulmuştur. Daha sonra ayrı bir kapta alçı ve silis 1:1 oranında hesaplanarak harmanlanmıştır. Ardından suyun alabileceği kadar silis ve alçı karışımı ilave edilmiştir. 
$\mathrm{Bu}$ işlemin tamamlanmasının ardından alçı karışımı, modelin kenarından yavaşça boşaltılmıştır (G. 3).

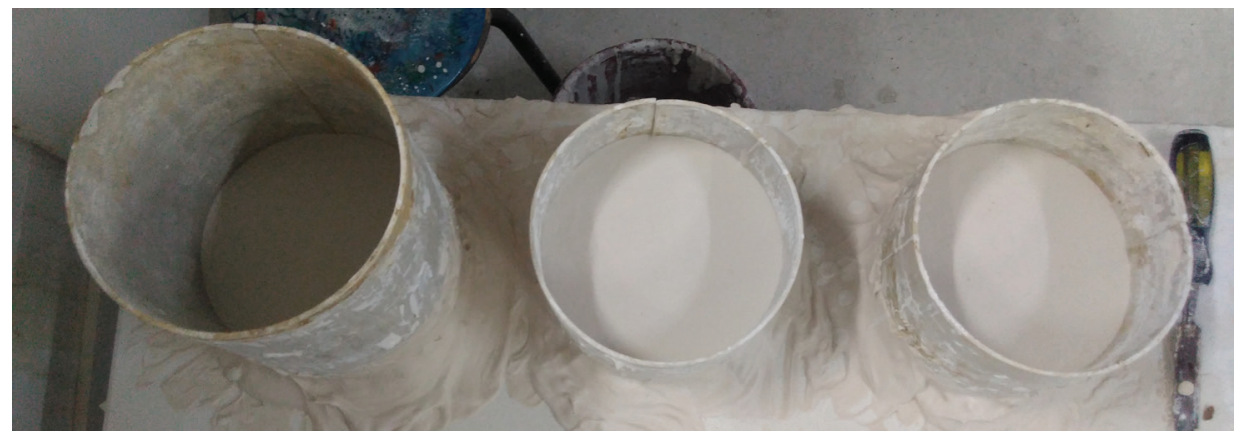

G. 3. Modellerin kalıplarının alınması (Özge Biçer, 2018)

Alçı donduktan sonra kurgular çıkartılarak kenarları düzeltilmiştir. Modeli sabitlemek için etrafına sıvanan çamur temizlenmiştir. Balmumu formu ısıya dayanıklı kalıbın içine yerleştirildikten hemen sonra tamamen buharlaştırılmalıdır. Cam külçeleri pişirimden önce kalıp boşluğunun içine konulmalı ya da kalıp üzerine yerleştirilen bir seramik potanın içine konularak ısı ile azar azar akıtılarak döküm yapılmalıdır. Bu yöntem kabarcıkların oluşmasını engellediği için daha çok tercih edilmektedir ${ }^{26}$. Bu çalışmalar sırasında, modeller el ile şekillendirildiği için balmumundaki katmanlar, kalıptan kolayca çıkmayı sağlamıştır (G. 4).
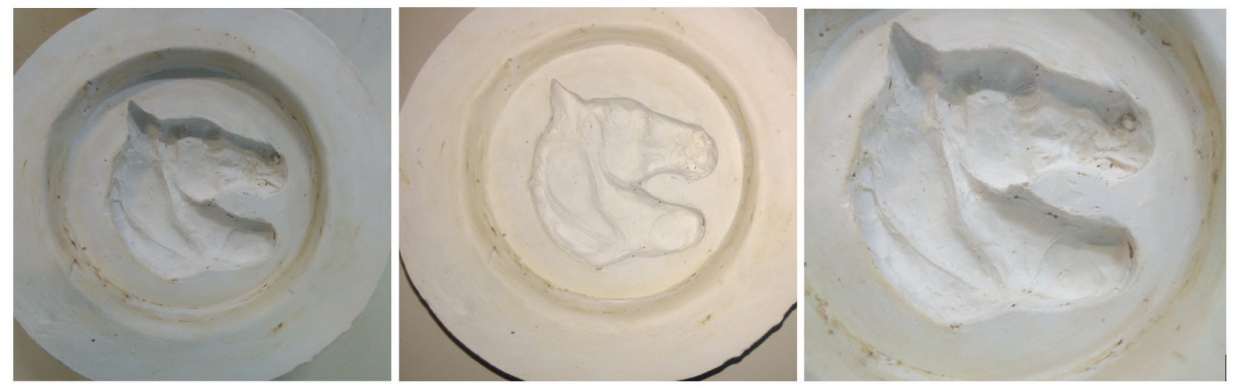

G. 4. Kalıpların içerisinden balmumlarının çıkartılması (Özge Biçer, 2018)

Alçı modellerin balmumlarından temizlenmesinin ardından camların hazırlanmasına geçilmiştir. Bu çalışma kapsamında, bir cam atölyesinin ambalaj atıkları ve imalat atıklarından yararlanılmıştır (G. 5). 

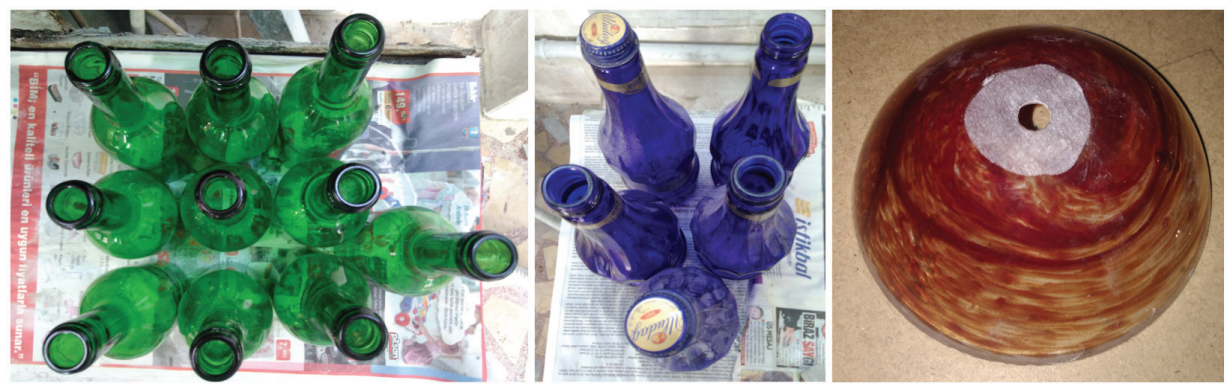

G. 5. Çalışmada kullanılan atık camlar (Özge Biçer, 2018)

Çalışmada 3 farklı cam atığı kullanılmıştır. Bu camlar arasında kullanılan mavi cam, bir maden suyu şişesine aittir. Kullanılan atık camın tavlama derecesi $560-580{ }^{\circ} \mathrm{C}$ arasındadır ve yumuşama sıcaklığ $750^{\circ} \mathrm{C}^{\prime}$ dir. Kullanılan yeşil camın tavlama sıcaklığ 1 $550^{\circ} \mathrm{C}$ 'dir. Yumuşama aralığ 1 ise $720^{\circ} \mathrm{C}$ 'dir. Çalışmada denenmek üzere kullanılan bir diğer cam, atölyede yapılan bir üretimin sonunda atık olarak kalan parçaların geri dönüştürülmesi amacı ile kullanılmıştır. Şeffaf camlar, Alman Cristalica COE 96 camlarıdır. Renkli camlar, Alman Kugler camlarına aittir. Isıl genleşme katsayıları birbirlerine yakındır. Daha önceden üretimi yapılmış camların birlikte kullanılmasından kaynaklı olarak herhangi bir uyumsuzluğa rastlanmamıştır. Kullanılacak olan atık camlar, yüzeylerinde bulunan kirlilikler aseton yardımı ile temizlenerek firınlama işlemine hazır hâle getirilmiştir (G. 6).
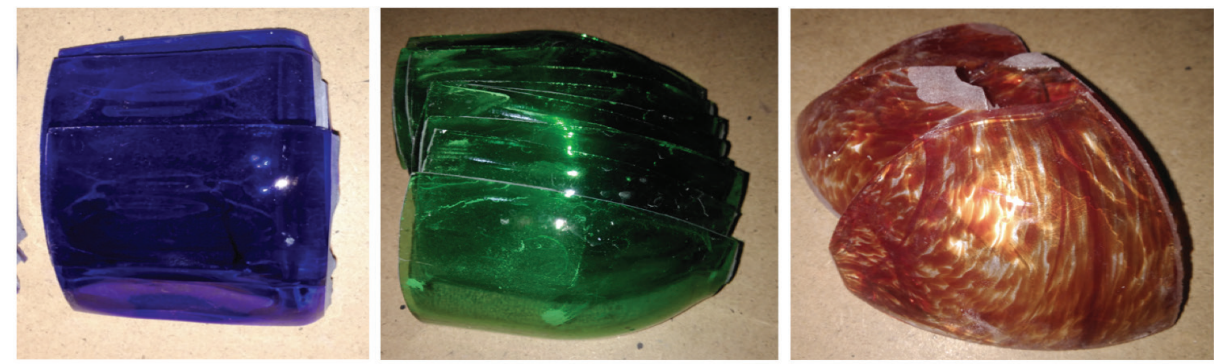

G. 6. Fırınlama öncesi temizlenen camlar (Özge Biçer, 2018)

Hazırlanan camlar, kalıplara tek tek yerleştirildikten sonra firına konulmuştur. Her bir modelde bulunan cam miktarı 640 gr'dır (G. 7). Bu aşamada daha şeffaf bir görünüm sağlamak amacıyla firına konulan camların boyutları mümkün olduğunca büyük tutulmuştur. 

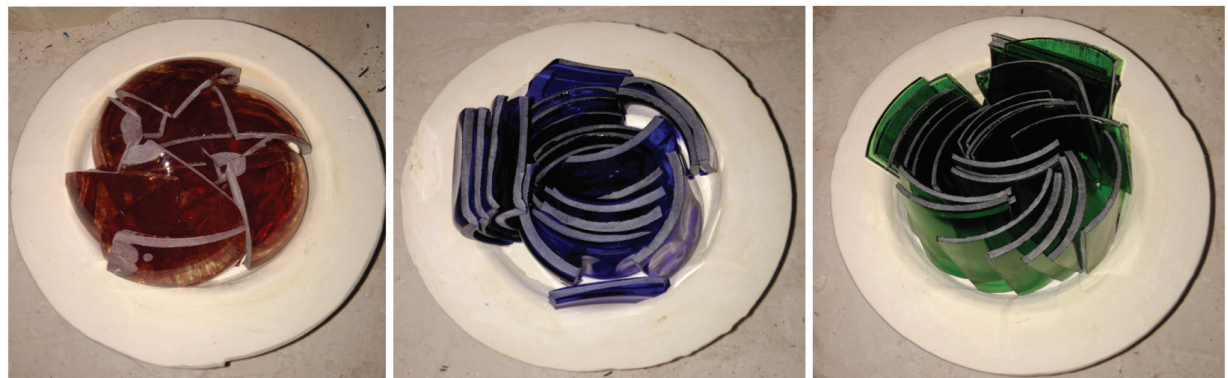

G. 7. Camların kalıplara yerleştirilmesi ve fırına konulması (Özge Biçer, 2018)

Tablo 1

Firın diyagrami ${ }^{27}$

\begin{tabular}{|c|c|c|}
\hline Skip & $85^{\circ}$ & $480^{\prime}$ \\
\hline $360^{\prime}$ & $590^{\circ}$ & $120^{\prime}$ \\
\hline Skip & $850^{\circ}$ & $180^{\prime}$ \\
\hline Skip & $560^{\circ}$ & $180^{\prime}$ \\
\hline $480^{\prime}$ & $400^{\circ}$ & $120^{\prime}$ \\
\hline $480^{\prime}$ & $50^{\circ}$ & - \\
\hline 0 & - & - \\
\hline
\end{tabular}

Tablo 1'de atık camlara uygulanan fırın diyagramı sunulmuştur. Camlar firından çıkarıldıktan sonra (G. 8) finisaj işlemleri uygulanmıştır.
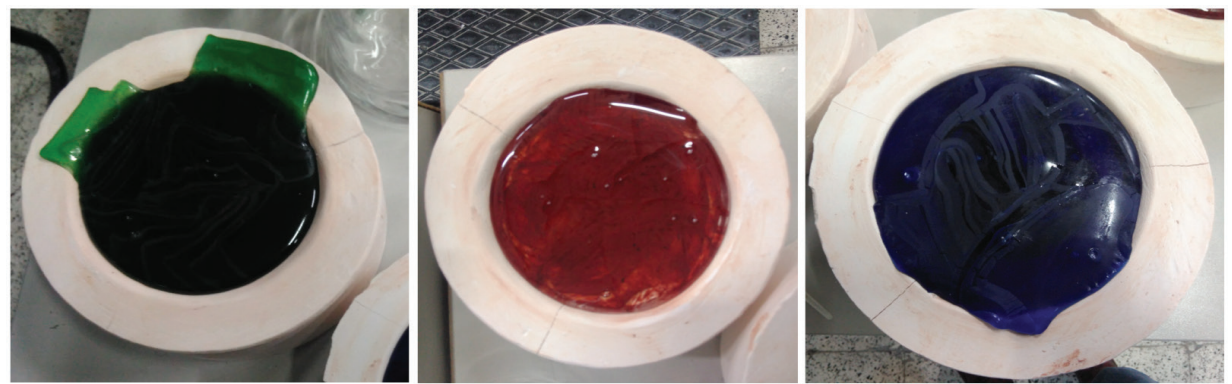

G. 8. Camların firından çıkartılması (Özge Biçer, 2018)

Modelin kenar kısımları soğuk cam şekillendirme tekniklerinde camın daha hızlı aşınması için kullanılan kum taşında düzeltilmiştir. Camın, kum taşındaki uygulama sonrasında ya da camın kenarlarında bulunan sıçrakların temizlenmesi için "zeim işlemi” uygulanmıştır. Bu işlemin önce yapılmasının nedeni, kenarların düzeltilmesi esnasında yüzeyden parça kopmasının engellenmesidir. Burada işlemin bitirilmesinin ardından, yüzeyde bulunan kumların temizlenmesi için "malatura tezgâhı" kullanılmıştır. İşlemin bitirilmesi ile kenarlar kum izlerinden arındırılarak istenilen form elde edilmiştir (G. 9). 

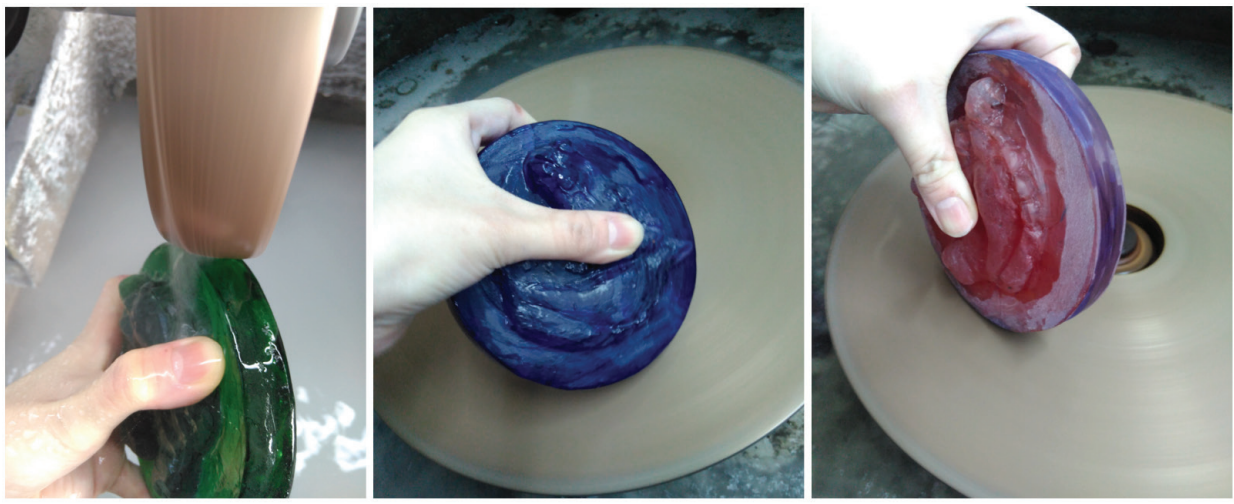

G. 9. Fırından çıkartılan camlara finisaj işlemlerinin uygulanması (Özge Biçer, 2018)

Kumlama işlemi için hazır hâle getirilen camların matlaştırılmak istenilen yüzeylerine basınçla püskürtülen kum taneleri, saydam camın geçirgenliğini azaltmış ve camların yüzeyinin pürüzlü bir yapıya sahip olmasını sağlamıştır (G. 10).
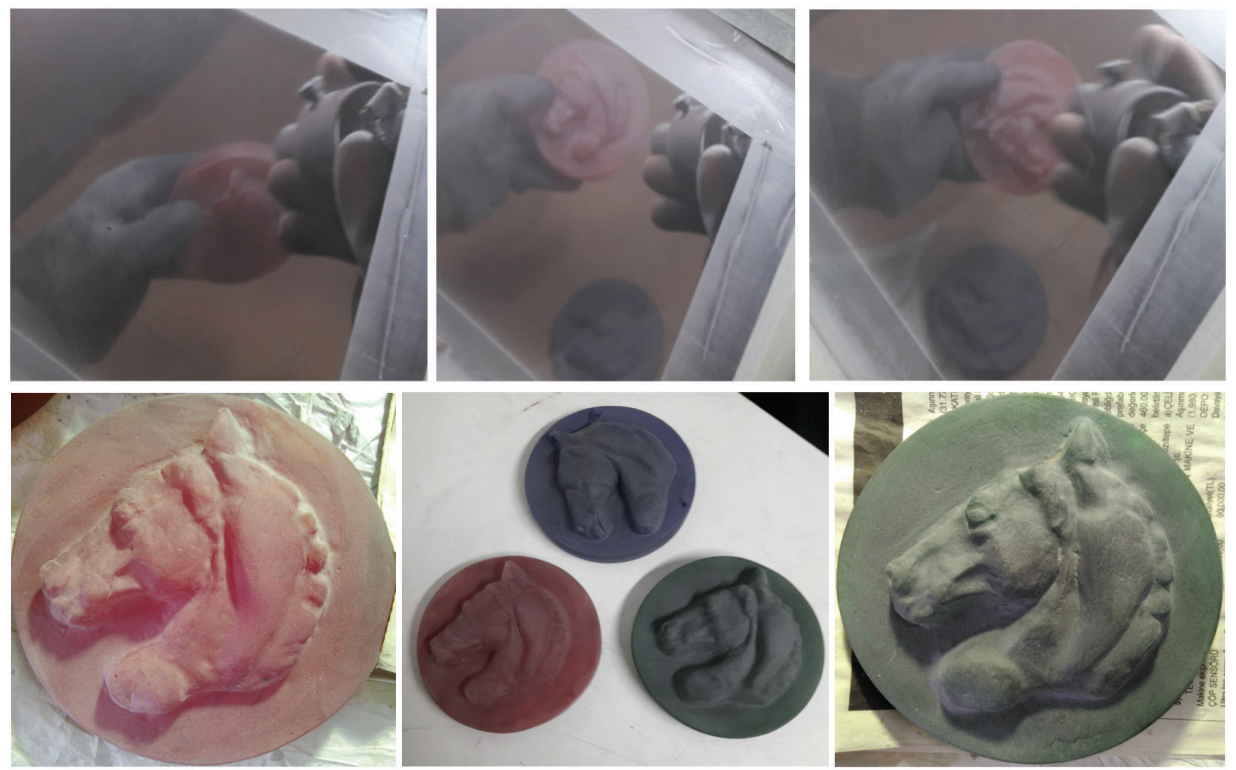

G. 10. Kumlama işlemi (Özge Biçer, 2018)

Tüm camlara kumlama işlemi uygulanmıştır. Ardından açma işlemi ile boyut kazandırılmıştır. Bu işlem, eskiden dekor uygulamalarının yapıldığı karbosan tezgahına takılan bez kafalarda yapılmıştır. Uygulamada yüzey tamamen parlatılmamış, yarı parlatma yani açma işlemi uygulanmıştır. Yüzeye uygulanan kumlama işlemindeki matlık kırılmıştır (G. 11). 

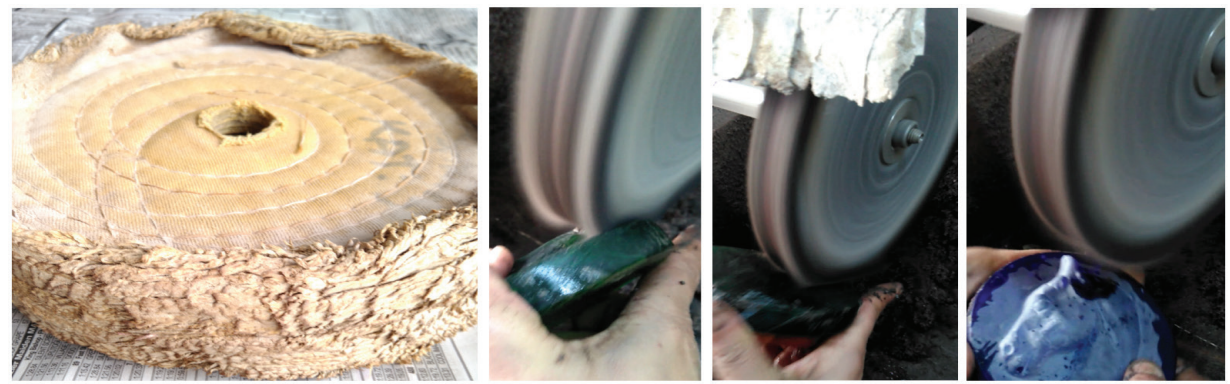

G. 11. Bez kafada camlara açma işleminin uygulanması (Özge Biçer, 2018)

Elde edilen cam örneklere ait görseller G.12'de sunulmuştur:
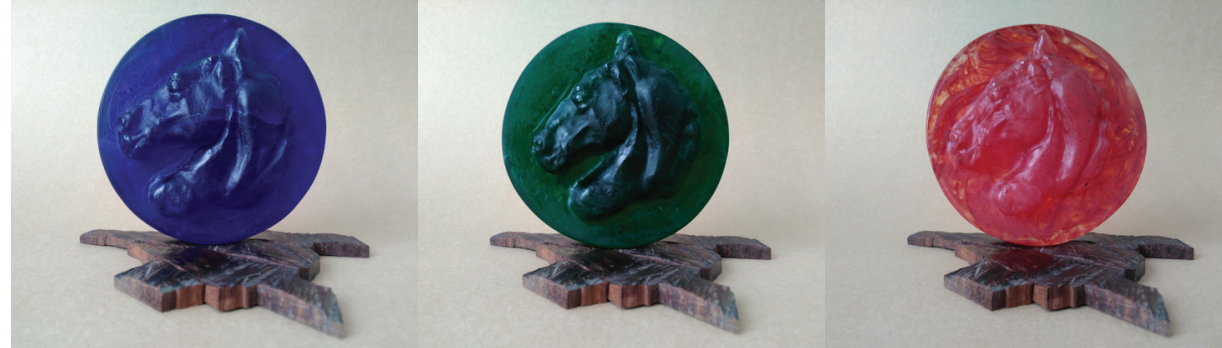

G. 12. Üretilen cam örneklere ait fotoğraflar (Özge Biçer, 2018)

Farklı renklerdeki atık camların kullanımı ile ışığı yansıtma özelliği ve dokusal etkisi değişebilen, özgün tasarımlara sahip özellikte sanatsal ürünlerin elde edilebileceği görülmektedir. G.13.'te çalışma kapsamında kalıpla şekillendirme tekniğinde atık cam kullanılarak üretilen camlar görülmektedir. Tablo 2'de ise bu camlarda kullanılan firın diyagramları yer almaktadır.

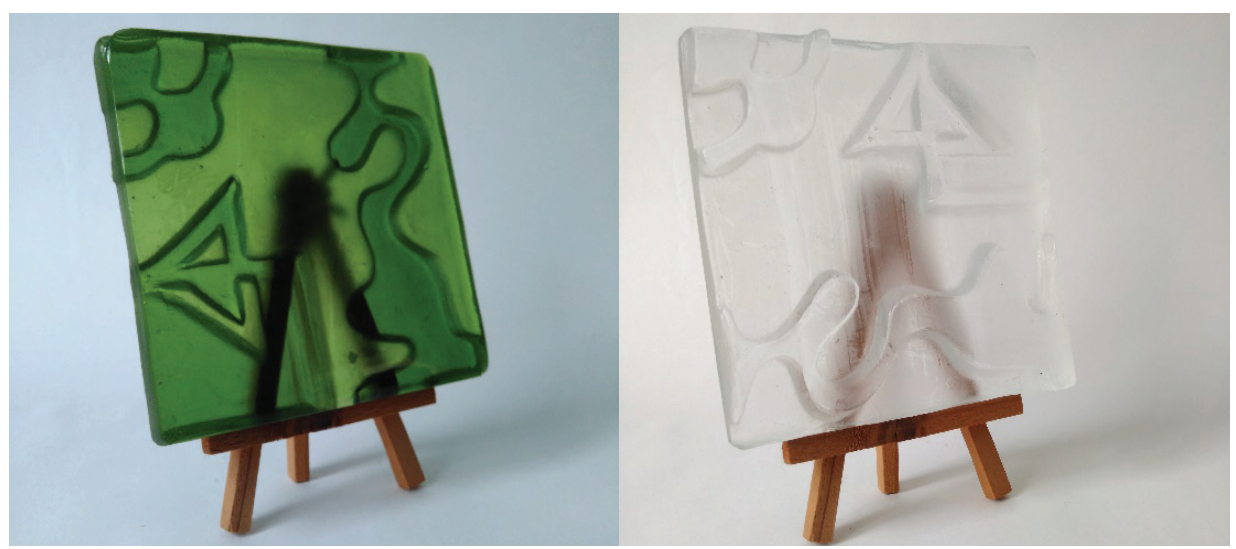

G. 13. Çalışma kapsamında üretilen cam eserler (Özge Biçer, 2018) 
Tablo 2

G.13'te sunulan çalıșmalar için kullanılan fırın diyagram ${ }^{28}$

\begin{tabular}{|c|c|c|}
\hline $60^{1}$ & $550^{\circ}$ & $5^{1}$ \\
\hline Skip & $820^{\circ}$ & $15^{1}$ \\
\hline Skip & $600^{\circ}$ & - \\
\hline $90^{1}$ & $400^{\circ}$ & - \\
\hline 0 & - & - \\
\hline
\end{tabular}

Bu uygulamada potadan geri dönüşüm için çıkartılan şeffaf camlar kullanılmıştır. Kullanılan bu camlar atölyede birincil hammadde olarak üretimde kullanılan cam türleridir. Alman Kugler camları ile Alman Cristalica COE 96 camlarının ısıl genleşme katsayıları birbirlerine çok yakındır. Kullanılan atölye camları arasında herhangi bir uyumsuzluğa rastlanmamıştır. Çalışma kapsamındaki camlar atık kutusundan ayrıştırılması sağlanarak uygulamada sadece bir el modeli üzerinde birlikte kullanılmış ve herhangi bir uyumsuzluğa rastlanmadığg gözlemlenmiştir (G. 14).

G.15.'te üretilmiş olan camlar, sıcak cam atölyesinde kullanılan pota camlarıdır. Şeffaf camlar Alman Cristalica COE 96 camlarıdır.

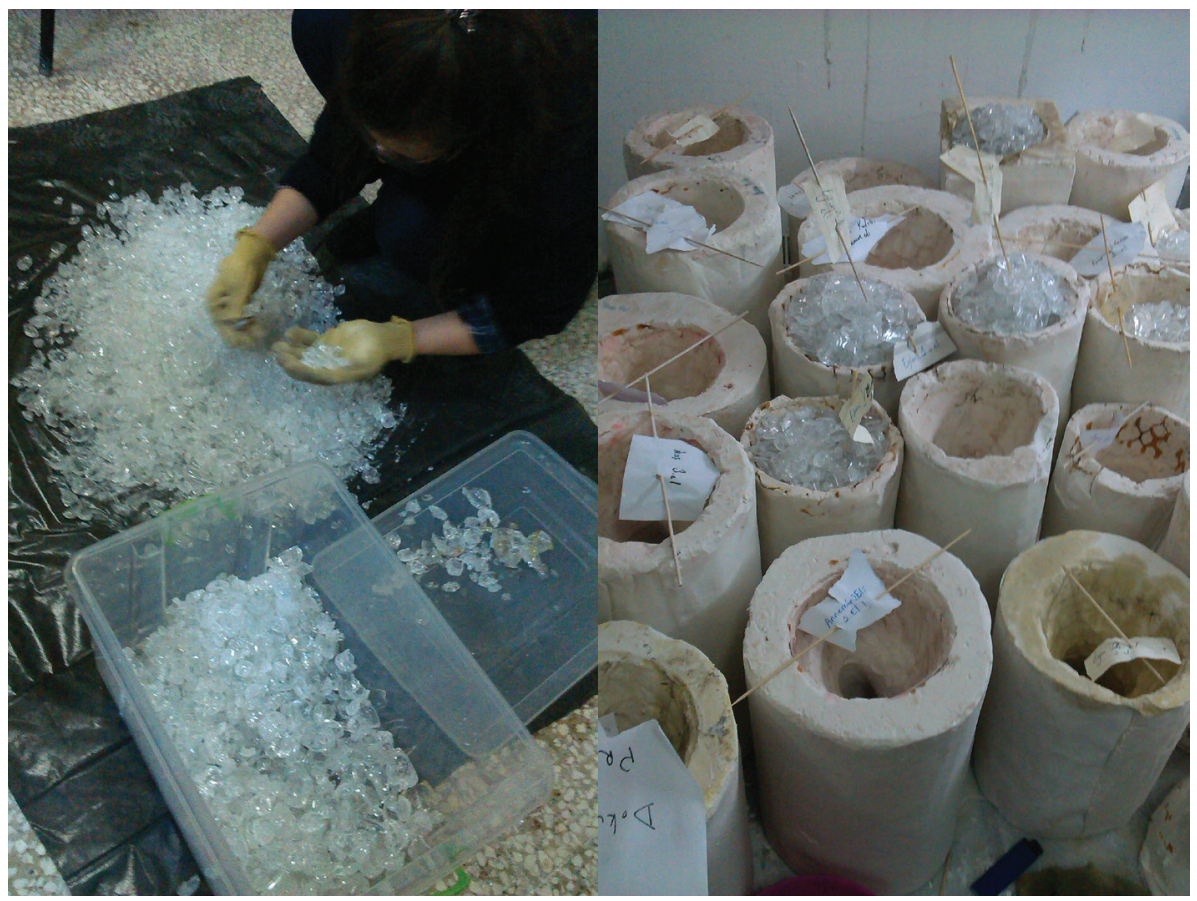

G. 14. Şeffaf atık camların ayrıştırılması (Özge Biçer, 2015)

28 Dr. Öğr. Üyesi İlhan Hasdemir tarafından hazırlanmıştır. 


\section{Tablo 3}

Atık Alman Kugler camlarının termal genleşme katsayısı, dönüşüm sıcaklığı, tavlanma noktası değerleri (https://www.kuglercolors.de/en/products/kugler-colors/colored-glass-rods/)

\begin{tabular}{|l|l|}
\hline Hesaplanan termal genleşme katsayıs1 & $96+4 \mathrm{x}^{10-7} / \mathrm{K}$ \\
\hline Dönüşüm sıcaklığ 1 & $469^{\circ}-500^{\circ} \mathrm{C}$ \\
\hline Tavlama noktası & $500^{\circ} \mathrm{C}$ \\
\hline
\end{tabular}

Tablo 4

G.15'te sunulan camlar için kullanılan firın diyagram $1^{29}$

\begin{tabular}{|c|c|c|}
\hline Skip & $100^{\circ}$ & $600^{1}$ \\
\hline $240^{1}$ & $550^{\circ}$ & $60^{1}$ \\
\hline $60^{1}$ & $830^{\circ}$ & $360^{1}$ \\
\hline Skip & $560^{\circ}$ & - \\
\hline $900^{1}$ & $460^{\circ}$ & $900^{1}$ \\
\hline $300^{1}$ & $300^{\circ}$ & $300^{1}$ \\
\hline 0 & - & - \\
\hline
\end{tabular}

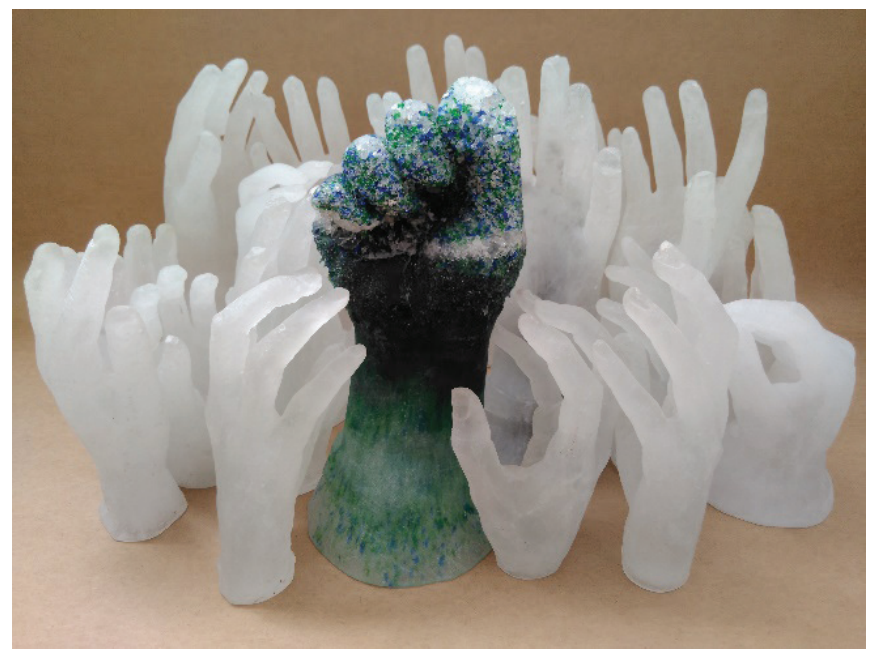

G. 15. Çalışma kapsamında üretilen cam eserler (Özge Biçer, 2015)

\section{Sonuç}

Sanayileşen ülkelerde, değişen yaşam koşulları, standartları, gün geçtikçe gelişen ve farklılaşan teknolojik ilerlemeler ile tüketim alışkanlıklarının değişmesi ve buna bağlı olarak artan insan nüfusu, tüketimin de artmasını beraberinde getirmiştir. Doğal kaynakların dikkatlice kullanılmadıkları takdirde bir gün tükeneceği kuşkusuzdur. Gelişen ve değişen dünya ekonomisinde, refah düzeyini her geçen gün yükseltmek adına yapılan çalışmalar, enerji tüketimi, çevre kirliliği gibi sorunları ortaya çıkartmaktadır.

Kaynaklardaki israfın önlenmesi amacıyla, atıkların azaltılması, yeniden kullanımı, geri dönüşümü ve enerji olarak geri kazanımı açısından ciddi çalışmalar yapılmak-

29 Dr. Öğr. Üyesi İlhan Hasdemir tarafından hazırlanmıştır. 
tadır. Geri kazanım sağlanamadığı zamanda fiziksel ve kimyasal olarak dönüşümü mümkün olmayan atıkların bertaraf edilmesi, uygulanan atık yönetimlerinin temel prensibi hâline gelmiştir. Dünyada, atıkların oluşumunu engellemek ve oluşan atık alanlarını mimimum düzeye indirmek amacı ile yapılan çalışmalar sıfır atık projeleri kapsamında devam etmektedir.

Geri dönüşümü sağlanan ambalaj atıklarının, sağlıklı bir dönüşüm zincirini oluşturması için ambalaj atığ yönetmeliği kapsamında, belediyelerin her mahalleye sağladığ 1 atık toplama kumbaralarında, kaynağında biriktirilerek düzenli olarak toplama noktalarına gönderilmesi sağlanmaktadır. Bu aşama atıkların toplanması ve ayrıştırılmak üzere işleme tesislerine gönderilmesi basamağına yardımcı olmaktadır. Çünkü atıkları kaynağında ayırmak, geri dönüşüm sürecine önemli katkılar sağlamaktadır.

Atık camlar, ham madde olarak tekrar imalat süreçlerine dâhil edildiğinde dönüşüm halkasına girmiş olur. Katı atıkların büyük bir yüzdesini oluşturan cam atıklarının geri dönüştürülmemesi; doğal kaynak, doğal çevre, ekonomi, enerji gibi birçok alanda olumsuz sonuçlara sebebiyet vermektedir.

Cam ambalaj atıkları, dünyada hammadde bakımından üretimde en fazla oranla kullanılan malzemelerdendir. Atık cam, kağıdın ve plastiğin aksine sonsuz kez geri dönüşümü sağlanan ve bir tek cam piyasasına katkı sağlamakla kalmayıp seramik, inşaat, beton hammaddesi, dekoratif malzeme, asfalt hammaddesi, metal döküm endüstrisinde katkı malzemesi, boya ve plastikte dolgu malzemesi gibi birçok farklı sektöre de katkısı bulunan önemli bir malzemedir. Cam atıkların biriktirilmesi, toplama merkezlerine gönderilmesi, renklerine göre ayrıştırılması, ardından metal ve kağıt gibi maddelerden ayrıştırılarak son kontrollerinin yapılarak sınıflandırılması ile renklerine göre üretimde yeniden yer alması sağlanmaktadır.

Çalı̧̧ma kapsamında atık camların kalıpla şekillendirme tekniğinde kullanılmalarıyla, cam sanatına sağlayabileceği katkılar irdelenmiş, sanatsal cam üretiminde daha fazla kullanılmalarının yolları araştırılmıştır. Bu çalışmada kullanılan camlar, ambalaj ve işletme atıklarından toplanılarak sanatsal bir boyuta taşınmıştır. Isıl genleşme katsayısı uyumsuzluğu olmaması için işletmede aynı üretimden çıkan camlar tercih edilmiştir. Çalışmalar kapsamında yalnızca iki çalışmada birbirlerine uyumlu farklı camlar bir arada kullanılmıştır. Camların genleşme katsayıları birbirlerine çok yakındır. Kullanım sonrasında camların yüzeyinde herhangi bir çatlama ya da kırılmaya rastlanmamıştır.

Kalıp içi cam şekillendirme yöntemi çok kapsamlı ve bir o kadar da uğraş gerektiren önemli bir teknik uygulama alanıdır. Malzemenin kullanımı ve üretim aşamaları, özgün tasarımlar ile birleştirilerek atık camların, fırın içerisindeki davranışları, nihai yüzey ve renk etkileri gözlemlenerek üretim parametreleri tartışılmıştır. 
Hakem Değerlendirmesi: Dış bağımsız.

Çıkar Çatışması: Yazarlar çıkar çatışması bildirmemiştir.

Finansal Destek: Yazarlar bu çalışma için finansal destek almadığını beyan etmiştir.

Peer-review: Externally peer-reviewed.

Conflict of Interest: The authors have no conflict of interest to declare.

Grant Support: The authors declared that this study has received no financial support.

\section{Kaynakça/References}

Aydın Tavukçu, Zerrin. "Parion Güney Nekropolü’nden Bir Grup Cam Eser.” Atatürk Üniversitesi Güzel Sanatlar Fakültesi Dergisi 12 (2007): 145-161.

Canav Özgümüş, Üzlifat. Çağlar Boyu Cam Tasarım. İstanbul: Paşabahçe Ticaret Limited, 1978.

Cummings, Keith. Çăgdaş Cam Sanatı Fırın Teknikleri ve Uygulamalar. Çev. Mustafa Ağatekin. İzmir: Karakalem Kitabevi, 2011.

Cummings, Keith. Techniques of Kiln-formed Glass. ABD: University of Pennsylvania Press, 1997.

Çak1, Münevver, Bekir Karasu, Selvin Yeşilay, Rahmi Irmak ve Canbora Bayraktar. "The Use of Fired Roof Tile and Brick Wastes in Stoneware Bodies as Alternative Raw Maretials." Proceedings of the Rewas 2008 Global Symposium on Recycling, Waste Treatment and Clean Tecnology. Ed. Brajendra Mishra, C. Ludwig and Subodh K. Das (USA: The Minerals, Metals \& Materials Society, 2008), Vol. 3, 1541-1548.

Gökçigdem, Elif. "Fragile Beauty: Islamic Glass”, Saudi Aramco World (May/June 2002): Erişim 27 Ocak 2020. https://archive.aramcoworld.com/issue/200203/fragile.beauty-islamic.glass.htm

Küçükbiçmen, Esin. “Cam Şekillendirme Yöntemleri ve Kişisel Yorumlar.” Sanatta Yeterlilik Tezi, Anadolu Üniversitesi, 2005.

Küçükerman, Önder. Cam ve Çağdaş Tasarım İçindeki Yeri. İstanbul: Paşabahçe Ticaret Limited, 1977.

Letelier, Viviana, Bastian I. Henriquez-Jara, Miguel Manosalva, Camila Parodi and Jose Marcos Ortega. "Use of Waste Glass as A Replacement for Raw Materials in Mortars with a Lower Environmental Impact." Energies 12 (2019): 1-18.

Mohajerani, Abbas, John Vajna, Tsz Ho Cheung, Halenur Kurmus, Arul Arulrajah and Suksun Horpibulsuk. "Practical Recycling Applications of Crushed Waste Glass in Construction Materials: A Review." Construction Building Materials 156 (2017): 443-467.

Öbelik, Yusuf. “Cam Hammaddesi Mineralojisi ve Cam Teknolojisi.” Yüksek Lisans tezi, Niğde Üniversitesi, 2011.

Öz, Ayşe. “Camın Geri Dönüşüm Süreci ve Çevre,” (Mart 2007). Erişim 7 Kasım 2018. http://www. kocaeliaydinlarocagi.org.tr/Yazi/Detay/32

Rahim, Nur Liza, Roshazita Che Amat and Norlia Mohamad Ibrahim. "Utilization of Recycled Glass Waste as Partial Replacement of Fine Aggregate in Concrete Production." Materials Science Forum 20 (2015): 16-20.

Schuler, Frederic and Lilli Schuler. Glassforming Glassmaking For The Craftsman. Londra: Pitman Publishing, 1971.

Sönmez, Barış Emre. “Nevşehir Müzesi'nde Bulunan Cam Unguentariumlar”. Uluslararası Sosyal Araştırmalar Dergisi 41 (2015): 733- 746. 
Sümer, Güner. Cam Teknolojisi. Eskişehir: [y.y.] 2007.

Şenok, Necati. "Pate De Verre Cam Şekillendirme Tekniği ile Cam Sanat Objeleri Araştırma ve Uygulamaları.” Yüksek Lisans tezi, Çukurova Üniversitesi, 2011.

Thwaites, Angela. Mould Making For Glass. New York: A\&C Black Visual Arts, 2011.

Uzuner, Bilgehan. Bulunuşundan Üflemeye Cam Teknikleri. İstanbul: İnk1lap Kitabevi, 2004.

Xi, Yunping, Yue Li, Zhaohui Xie and Jae S. Lee. "Utilization of Solid Wasted (Waste Glass and Rubber Particles) as Aggregates in Concrete". Proceedings of the International Workshop on Sustainable Development and Concrete Technology. Ed. Kejin Wang (ABD: Iowa State University, 2004), 45-54.

Yeşilay, Selvin. “Cam Dekorasyon Teknikleri.“ Anadolu Sanat Dergisi 19 (2008): 111-116.

Yeşilay, Selvin ve Ufuk Akbey. "Cam Dekorasyonunda Alternatif Bir Malzeme Olarak Uçucu Kül Kullanımının Araştııılması.” Sanat ve Tasarım Dergisi 20 (2017): 301-313.

Haberler. “Bodrum'da Atık Camlar Sanata Dönüşüyor.” Erişim 5 Kasım 2019. https://www.haberler. com/atik-camlar-sanata-donusuyor-6212913-haberi/.

Insteading. "Glass Bottle Windows.” Erişim 5 Kasım 2019. https://insteading.com/blog/recycledglass-bottles/.

https://www.kuglercolors.de/en/products/kugler-colors/colored-glass-rods/. 9 Mayıs 2020.

Technology Policy Update. "Ivan Bestari and Otakatik studio Color Pattern Artwork Miniature Sculpture Glass Materials.” Erişim: 5 Kasım 2019.

https://www.tinuku.com/2016/09/23.html. 